\title{
ASSISTÊNCIA PRIMÁRIA EM SAÚDE - ATUAÇÃO DO ENFERMEIRO FRENTE AS NECESSIDADES DO PORTADOR DE MALFORMAÇÃO CONGÊNITA DE LÁBIO EIOU PALATO
}

Ana Márcia Crisci Bertone ${ }^{1}$ Sandra Thomé ${ }^{2}$ Maria Irene Bachega ${ }^{3}$

RESUMO: Neste relato, destacamos a experiência e a evolução da assisténcia de enfermagem no serviço ambulatorial do Hospital de Pesquisa e Realibilitação de Lesões Lábio Palatais da Universidade de São Paulo, em Bauru-SP, que visa obter os resultados mais adequados possíveis a niveis estético, funcional e psico-social na reabilitação do portador de fissura de lábio e/ou palato. Ressaltamos também a importåncia da participação ativa do cliente e família no conhecimento de seus problemas de saúde para uma completa reabilitação.

UNITERMOS: Fissura Lábio-Palatal - Assistência Primária - Reabilitação

\section{I - INTRODUÇÃO}

O presente trabalho foi elaborado levandose em consideração a experiência vivenciada pelas enfermeiras do Hospital de Pesquisa e Reabilitação de Lesões Lábio Palatais (HPRLLP) da Universidade de São Paulo-Bauru e tem como objetivo descrever a evolução da atuação de enfermagem no que diz respeito à assistência primária aos portadores de má formação congênita de lábio e/ou palato (fissuras de lábio e/ou palato), associadas ou não a outras alterações crânio-faciais.

O HPRLLP foi fundado em junho de 1967 e tem como finalidade prestar assistência global aos portadores de más-formações congênitas crânio-faciais, dentro dos padrőes técnicos e científicos necessários a cada caso, visando a reabilitação de seus clientes através da atuação da equipe interdisciplinar. Cabe aqui lembrar a importância da participação ativa do cliente na definição e entendimento de seus problemas de saúde para sua completa reabilitação. Tal participação, incluindo família e comunidade, pode e deve ser permitida e incentivada pelo enfermeiro inserido no contexto geral dos problemas a niveis estéticos funcionais, psicológicos e sociais que as fissuras podem acarretar.

\section{II - CONSIDERAÇÕES GERAIS SOBRE FIS- SURA LÁBIO PALATAL}

As malformações congênitas de lábio e palato são conhecidas popularmente com "lábio leporino e "goela de lobo".

O conhecimento da fase embriológica dos processos faciais é fundamental para o entendimento das malformações congênitas aí localizadas. Segundo SILVA FILHO (1986), a face humana se forma entre a $4^{a}$ e $9^{a}$ semana após a concepção, envolvendo um mecanismo complexo de proliferação celular, diferenciação e migração, que resultam na junção e coalescência dos processos faciais embrionários.

Segundo SPINA (1984), fissura labial é aquela onde o desenvolvimento do lábio ocorre de forma anormal e os processos que dão origem ao lábio superior não se fundem completamen-

1 Enfermeira responsável pela Central de Saúde Pública do Hospital de Pesquisa e Reabilitação de Lesões Lábio Palatais (HPRLLP) - USP, Bauru-SP. COREN/SP 30747.

2 Diretora Técnica do Serviço de Enfermagem do HPRLLP - USP, Bauru-SP. COREN/SP 15413

3 Diretora Técnica de Serviços Complemenetares e Tratamento Hospitalar do HPRLLP-USP, Bauru-SP. COREN/SP 14665. 
te, originando uma fenda que pode ser uni ou bilateral, e a fissura de palato é falta de união dos processos palatinos, de maneira a deixar uma fenda de extensão e largura variáveis desde a úvula até o forame incisivo, sendo comum a associaçăo desses dois tipos de fissura.

Existem vários critérios de classificação das fissuras sendo que o HPRLLP baseia-se no de SPINA et al. (1972) que toma como referéncia o forame incisivo - ponto de junção na formação de toda a regiåo lábio palatina.

$O$ autor referido classifica as fissuras em quatro grupos:

\section{Grupo I - fissuras pré forame incisivo (fissuras labiais) \\ A - Unilaterais \\ Completa: direita ou esquerda \\ Incompleta: direita ou esquerda \\ B - Bilaterais \\ Completa ou completa de ambos \\ os lados ou incompleta de um lado \\ e completa do outro. \\ C - Medianas}

Grupo II - fissuras pós forame incisivo (fissuras palatais)

Completa

Incompleta

Grupo III - fissuras transforame incisivo (fissuras lábio palatais)

Unilaterais: direita ou esquerda

Bilaterais

Grupo IV - fissuras raras da face

A incidência de individuos que nascem com malformações lábio palatais no Brasil é elevada, ou seja, cerca de 1: 650 nascimentos (NAGEM FILHO et al, 1968; FONSECA, REZENDE, 1971; SOUZA FREITAS et al, 1977). Além disso, a maior incidência ocorre entre os japoneses e a menor entre os negros, de acordo com GREENE et al, (1964) e GREENE (1968).

Ainda segundo os autores referidos acima, as fissuras lábio-palatais são mais freqüentes no sexo masculino, enquanto que as do palato ocorrem mais freqüentemente no sexo feminino.

A etiologia da malformação lábio palatal é desconhecida. Admite-se, porém, que fatores ambientais, genéticos ou ambos podem levar à sua ocorréncia. SOUZA FREITAS et al, (1974) destacam que os fatores ambientais ou nutricionais, tóxicos, endócrinos, anatómicos, infecciosos, psíquicos, idade de concepção, podem ser causadores das deformidades congênitas.

Ressaltam ainda que familiares com histórias de fissuras lábio-palatais apresentam a seguinte probalidade de ocorrência:

- pais normais: $0,1 \%$ de possibilidade de um filho "fissurado".

- um dos pais "fissurados": $2 \%$ de possibilidade de um filho "fissurado".

- pais normais e um filho "fissurado": $4,55 \%$ de possibilidade de ter outro filho "fissurado".

- um dos pais e um filho "fissurados": $15 \%$ de possibilidade de ter outro filho "fissurado".

No Brasil estima-se cerca de 220.000 portadores de fissura. As fissuras congénitas de lábio e/ou palato são, das malformações faciais, as mais freqüentes e constituem uma gama de problemas que exigem a atuação segura e eficaz do enfermeiro.

As implicações estéticas, funcionais e psicosociais decorrentes da fissura exigem tratamentos complexos e integrados, de acordo com cada fase do desenvolvimento.

Dentre tais implicações evidenciam-se inicialmente, com o nascimento da criança portadora de fissura, o impacto e a reação dos pais, que abalam a integração da familia e os problemas alimentares aos quais essa criança está sujeita.

A aceitação da família em relação ao problema, parece variar de acordo com a classe sócio-cultural. Segundo GRACIANO (1988) quanto menor for a classificação sócio-econômica, maior é a "aceitação" do problema.

Observa-se que nas classes sociais mais baixas, os padrões culturais estão mais voltados às crendices populares, superstições, além dos valores teológicos, levando a família a atri- 
buir a ocorrência da fissura aos fatores citados acima. Já nas classes sociais mais elevadas, a aceitação é menor, pelo fato de as familias serem mais conscientes dos vários problemas $\mathrm{e}$ dificuldades que deverão ser enfrentados. Surgem dúvidas quanto à alimentação, tratamento, cirurgia, enfim, tudo o que diz respeito ao desenvolvimento da criança.

Com relação à alimentação, as crianças portadoras de fissuras, em especial aquelas com fissuras de lábio e palato, encontram-se em desvantagem em relação às outras, sem deformidades orais.

De acordo com PARADISE, MC WILLIAMS (1974), as crianças com fissura de lábio e palato não possuem capacidade de sucção adequada inicialmente, correm o risco de bronco-aspiração e estão mais sujeitas à ocorrência de otites médias e processos infecciosos de vias aéreas superiores devido à comunicação entre as cavidades oral e nasal.

Além dessas dificuldades, outros distúrbios estão associados, como o problema fonoaudiológico e odontológico, ressaltando-se a ansiedade dos familiares em relação aos cuidados adequados que devem ser prestados às criancas.

Sabemos que o processo de crescimento e desenvolvimento da criança é contínuo e ininterrupto mas pode sofrer interferências na sua evolução na ocorrência de fatores negativos se não forem prevenidos.

Dentro deste contexto é necessário a atuação do enfermeiro junto a criança portadora de fissura e a familia, de maneira que todas as suas necessidades sejam atendidas (SHAPIRO, 1973).

Nossa experiência tem mostrado que mesmo os profissionais da área de saúde, muito pouco tem contribuido no sentido de prestar uma assistência adequada à criança com esse tipo de problema, levando as mães muitas vezes a atitudes inadequadas e, interferindo consequentemente, no desenvolvimento adequado da criança. Talvez isso se deva ao fato da escassa literatura que possuímos a esse respeito.

A participação do enfermeiro, juntamente com outros profissionais da equipe, devidamente conhecedor e voltado para esse problema é de grande valia. Para PEACOK, STARR (1980) a tarefa do enfermeiro é encorajar e instruir os pais tornando viável o sucesso de todas as medidas.

\section{III - ATUAÇÃO DO ENFERMEIRO NA CENTRAL DE SAÚDE PÚBLICA}

O HPRLLP possui uma central de saúde pública criada em 1981 tendo como responsáve! uma enfermeira de saúde pública, a qual, segundo BACHEGA et al (1985-a) tem como objetivo orientar, instruir e encorajar a educaçåo em saúde, proporcionando mudanças e interferindo na situação saúde, permitindo assim a participação do indivíduo, família e comunidade na reabilitação do fissurado lábio palatal.

A assistência aos pacientes.internados no HPRLLP desde a criação da Central de Saúde Pública, ainda segundo os autores referidos acima, obedecia um determinado cronograma no qual a contribuição do enfermeiro se dava através da pré e pós consulta de enfermagem. Faziam parte do atendimento de enfermagem, orientaçőes especificas relacionadas ao tipo de fissura, e gerais quanto aos cuidados básicos de saúde, de acordo com a faixa etária do cliente, ou seja: de 1 a 30 dias; de 31 dias a 1 ano; de 1 a 4 anos; de 4 a 12 anos e a partir de 12 anos.

Além das orientações já citadas, outras eram feitas ou reforçadas. Eram elas: condiçőes clínicas e laboratoriais exigidas para cirurgia, preparo para a internação e controle e encaminhamentoo para especialistas.

Embora através das pré e pós consultas pudéssemos obter uma série de informaçőes necessárias a uma boa assisténcia de enfermagem (individualizada), havia uma certa limitação para a execução de todas as atividades do enfermeiro uma vez que, além estarmos coletando dados para facilitar o atendimento médico, havia necessidade de atender o paciente duas vezes no mesmo período.

Além disso, houve o aumento da demanda de pacientes, oriundo da maior divulgação do Hospital. Dessa forma, embora o quadro de pessoal tenha sido aumentado, passamos a repensar na eficácia e qualidade do atendimento que vinha sendo prestado. 
A regulamentação do exercício da enfermagem, através da LEI no 7.498 de 25 de junho de 1986, que no seu artigo 11 designa privativamente ao enfermeiro, a consulta de enfermagem, ampliou o espaço para que as atividades do enfermeiro pudessem ser executadas de forma mais abrangente (considerando o indivíduo como um todo) e com meIhor qualidade.

Dessa forma, algumas reformulaçőes foram feitas a nivel das atividades do enfermeiro da Central de Saúde Pública do HPRLLP com relação à assistência primária ao portador de fissura lábio palatal tendo sido substituída, então, as pré e pós consultas, pela consulta de enfermagem (anexo).

A consulta de enfermagem é realizada a nivel ambulatorial a todas os pacientes em início de tratamento (casos novos) independentemente da faixa etária.

Além da realização da consulta de enfermagem onde prestamos um atendimento individualizado ao paciente, existem os agendamentos para controles ambulatoriais de enfermagem.

Em consonância às etapas terapêuticas estipuladas pela equipe multidisciplinar, o Serviço de Enfermagem estabeleceu condutas de atendimento ambulatorial de acordo com o tipo de fissura e faixa etária do paciente des de que não haja necessidade de atendimentos intermediários dependentes de intercorrências não previstas.

Assim, os enfermeiros, tanto quanto os outros profissionais, têm autonomia para solicitar os retornos que forem necessários.

Segue abaixo o esquema elaborado para atendimento de enfermagem de acordo com o tipo de fissura:

1) Fissura Pré Forame Incisivo:

Após o atendimento como caso novo realizamos avaliação e orientações aos 06 e 18 meses e aos $3,7,13$ e 18 anos de idade.

2) Fissuras Pós e Transforame Incisivo

Após o atendimento como caso novo realizamos avaliação e orientações aos 03,06,12 e 18 meses e aos $3,7,13$ e 18 anos de idade.
A partir dos 18 anos de idade, os retornos são solicitados de acordo com a necessidade.

Salientamos que nos retornos programados, a consulta de enfermagem é realizada de forma mais simplificada eliminando os dados não possíveis de modificação.

Além das condutas tomadas pelo enfermeiro, frente aos problemas levantados, seguimos para a assistência global um plano de orientações básico sobre:

- importância do controle médico periódico

- higiene oral e corporal

- avaliação do desenvolvimento neuro-psicomotor e pôndero-estrutural

- moléstias infecto-contagiosas

- verminose

- técnica de alimenetação

- condições exigidas para cirurgia

- esclarecimentos sobre internação

- vida social e afetiva

- desenvolvimento escolar

- atividades profissionais

- atividade sexual

- planejamento familiar

- profilaxia médicamentosa

- saneamento básico

- encaminhamento ao Centro de Saúde da cidade de origem quando necessário.

A enfermeira também participa na definição do diagnóstico do cliente e no tratamento a ser realizado, registrando os dados no prontuário.

Tendo em vista a dificuldade de locomoção da mãe e criança nos primeiros dias de vida, até o HPRLLP, uma vez que a maioria delas são procedentes de outras cidades, torna-se de extrema importância, o contato enfermeira $x$ família através do telefone para as orientações iniciais.

Existe na Central de Saúde Pública a unidade denominada "pediatria externa" com 8 leitos, áreas de higienização e de lactário anexas, onde permanecem as crianças com até um ano de idade em companhia da mãe. Isso tem contribuido para uma melhor definição de condutas por parte do enfermeiro uma vez que se pode adicionar às informaçőes verbalizadas pelas mães, a observação da interação mãe $x$ filho $e$ os cuidados prestados às crianças. 
Na referida unidade săo prestadas orientações básicas de cuidados e em especial com relaçăo às "técnicas"de alimentaçăo objetivando o mais adequado processo de crescimento e desenvolvimento da criança portadora de fissura.

A forma de alimentar a criança portadora de fissura, tem sido descrita por profissionais do HPRLLP como pode se observar, através dos trabalhos de BUENO et al (1980), BACHEGA et al (1985a), BACHEGA et al (1985b), THOMÉ et al (1990).

Com o decorrer do tempo e de acordo com as experiências vivenciadas na prestaçăo da assisténcia ao portador de fissura, no que diz respeito à alimentaçăo, sentimos a necessidade de obter mais subsídios para a orientaçăo do aleitamento materno tendo em vista todos os seus benefícios e em especial os efeitos benéficos que a sucção no peito produz com relaçăo ao desenvolvimento normal da face e, consequentemente, da fala por estimulaçăo de todo o sistema motor oral.

Nesse sentido, THOMÉ (1990) realizou um estudo, baseada nas informaçőes verbalizadas pelas mães, sobre a prática do aleitamento materno em crianças portadoras de fissura. Mostra no referido estudo as posiçס̃es preferidas pelas crianças para o aleitamento materno as quais variaram de acordo com o tipo, extensão e lateralidade da fissura.

É importante ressaltar que foram alteradas as orientaçőes que eram realizadas anteriormente para que as mães de crianças portadoras de fissuras que optaram pelo aleitamento materno, desmamassem seus filhos, gradativamente, a partir de seis meses de idade para que fossem submetidos à cirurgia de lábio.

Atualmente o incentivo ao aleitamento ma- terno é constante independentemente da idade com a qual a criança seja submetida à cirurgia.

As cirurgias de lábio e palato estăo indicadas em faixas etárias precoces e constituem uma das etapas importantes no contexto geral da assistência ao portador de fissura pois delas dependem outras etapas como por exemplo, a terapia fonoaudiológica, além de amenizarem problemas como as otites médias repetidas, a alimentação e outros peculiares aos portadores de fissura. Porém, tais cirurgias săo consideradas eletivas exigindo condiçőes clínicas e laboratoriais adequadas para sua realização visando diminuir os riscos anestésico-cirúrgicos.

Cientes da complexidade do tratamento e da necessidade de que o portador de fissura possa estar em condiçőes de submeter-se a todas as etapas do tratamento nas faixas etárias apropriadas, cabe ao enfermeiro que atende a nivel ambularorial prestar assistência que facilite ao cliente a manutenção de um estado de saúde adequado. Assim, a assistência de enfermagem integrada à de outros profissionais da equipe, tendem a propiciar o estabelecimento da reabilitação do portador de fissura da forma mais adequada possível.

\section{IV - CONCLUSÃO}

A assistência primária em saúde, ao portador de malformaçőes congênitas de lábio e/ou palato é de fundamental importância para a manutenção de condiçőes adequadas do cliente em seu processo de crescimento e desenvolvimento.

A integração equipe de saúde $x$ cliente $x$ família e comunidade proporciona meios para uma participaçăo ativa do cliente e família no processo de reabilitação. 
ABSTRACT: In this report, we detach the experience and the evolution of the nursery assistence in the ambulatorial service in the HPRLLP-USP-Bauru-SP, which aims to reach the most eficcient results in the aesthetic, functional and pshicosocial rehabilitation of those who have cleft lip or palate. We stand out the importance of active participation of the pacient and his family on the knowledgement of his health problems in order to improve a complete rehabilitation.

KEYWORDS: Cleft Lip and Palate - Primary Assistence - Rehabilitation

\section{REFERÊNCIAS BIBLIOGRÁFICAS}

01 - BACHEGA, M. I, et al. Central de Saúde Pública na Assistência Primária ao portador de fissura lábio-palatal. Rev. Bras. Enferm., v.38, p.156-168, 1985 (a).

02 O uso de mamadeiras ortodônticas para a alimentação de crianças com fissuras lábio-palatais. Pediat.Mod., v.20, p.367-371, 1985 (b).

03 - BUENO, A.G, et al. Reabilitação de lesões lábio-palatais: uma experiência de enfermagem. Rev. Bras.Enferm., v.33, p.242-252, 1980.

04 - FONSECA, E. P., REZENDE, R. R. V..Incidência das malformações do lábio e do palato. R. Fac. Odont.-USP, v.9, p.45-58, 1971.

05 - GRACIANO, M. I. G. De cliente a agente: os pais-coordenadores e sua ação multiplicadora num programa de lesões lábio-palatais. São Paulo, 1988. (Tese - Pontífica Universidade Católica de São Paulo)

06 - GREENE, J.C. Epidemiologic Research - 19641967. J. Amer. Dent. Ass., v.76, p.13501356, 1968.

07 - GREENE, J.C. et al. Epidemiologic Study of deft lip and deft palate in four States. J. Amer. Oent. Ass., v.68, p.387-404, 1964.

08 - NAGEM FILHO, H. et al. Contribuição para o estudo da prevalência das malformações congênitas lábio-palatais na população escolar de Bauru. R. Fac. Odont. São Paulo, v.6, p.111-128, 1968.

09 - PARADISE, J.L., MCWILLIANS, B. J. Simplified feed for infantis with clef palate. Pediatrics, v.53, p.566-568, 1974.
10 - PEACOCK, J.L.E., STARR, P. An outreach program for families of infantes with a clef lip and or palate. Child. Today, V.9, p.23-26, 1980.

11 - SHAPIRO, C.S. et al. Nursing care of the cleft lip. cletf palate child. RN, 36: 46-60, 1973.

12 - SILVA FILHO, O.G. da. Curso de malformação congênita lábio-palatal do Hospital de Pesquisa e Reabilitação de Lesões Lábio-Palatais. Bauru, 1986 (Boletim)

13 - SOUZA FREITAS, J.A. de et al. Malformações congênitas lábio-palatais. Cien.Cult., v.26, p.115, 1974(supl).

14

Pesquisas epidemiológica sobre lesões lábio-palatais e tratamento Destas anomalias congênitas. Cien.Cult., V.29, p.141, 1977 (supl).

15 - SPINA, V. et al. Classificação das fissuras lábio-palatinas: sugestão de modificação. $\mathbf{R}$. Hosp. Clín.Fac.Med. São Paulo, v.27, p.56, 1972.

16 - SPINA, V. Fissuras congênitas e lábio palatinas: generalidades. In: ZERBINI, E.J. (ed). Clínica Cirúrgica Alípio Correa Netto. São Paulo: Sarvier, 1984. p.305.15.

17 - THOMÉ, S. Estudo da prática do aleitamento materno em crianças portadoras de malformação congênita de lábio e/ou de palato. Ribeirão Preto, 1990. (Tese - Escola de Enfermagem de Ribeirão Preto da Universidade de São Paulo)

18 - THOMÉ S. et al. Assistência de enfermagem à criança portadora de fissura lábio palatal. $\mathbf{R}$. Paul. Enferm., v.9, p.11-16, 1990. 
VI - ANEXO

Consulta de Enfermagem - Caso Novo

I - Histórico de Enfermagem

Nome

RG

Data

Tipo de fissura

\section{1) Antecedentes}

Pré Natais

- Tempo de gestação:

a termo ( ) pré termo ( ) pós termo ( )

- Intercorrências:

Peri Natais

- tipo de parto ( ) normal ( ) cirúrgico ( ) fórceps

- peso ao nascer altura ao nascer

- intercorrência com a criança

- como recebeu a criança?

Mórbidos

- doenças apresentadas (viroses gerais e respiratórias, pneumonias, crises convulsivas, alergias, acidentes, febre, moléstias infecto contagiosas)

- tratamento empregado inclusive cirurgias

- periodicidade de controle de saúde

- já ficou hospitalizado: ( ) sim ( ) não Por que?

\section{Familiares}

- história de doença (diabetes, hipertensão, TB, neoplasias, doenças cárdio - vasculares, doenças mentais, fissura lábio-palatal, etc.)

2) Uso de Medicamentos (vitaminas, anticonvulsivantes, anti alérgicos, antibióticos, etc.), quantidade, modo de uso e com que idade iniciou?

\section{3) Situação de Saúde}

- imunização em dia ( ) sim ( ) não

- higiene (corporal, bucal, vestuário, utensilios para alimentação, lavagem da roupa do bebé)

- saneamentoo básico:

- condições de moradia ( $n^{\circ}$ de cômodos, procedência da água, destino do lixo e dejetos)

- presença de animais domésticos

- eliminações
- urinária ( ) sem anormalidades

( ) com anormalidades quais:

- intestinal ( ) normal para idade

( ) diarréias frequentes

( ) obstipação

( ) outros

- já teve sua primeira menstruação?

() não em que idade?

Gostaria de saber mais a respeito de menstruação?

( ) sim ( ) não

Toma medicação?

O seu ciclo menstrual é de quantos dias?

Já iniciou atividade sexual?

( ) sim ( ) não

Está usando algum método anticoncepcional"?

( ) sim ( ) não

Gostaria de alguma informação?

( ) sim ( ) não quais:

- Alimentação

- tipo de alimentação ao nascer

( ) natural ( ) artificial

- época do desmame por que?

- alimentação atual (tipo, freqüência e quantidade)

- técnica alimentar empregada:

( ) seio ( ) mamadeira ( ) S.N.G.

( ) conta gotas ( ) colher

( ) come sozinha

outros

- apetite: ( ) bom （）regular ( ) ruim

- restrições

- alterações (vômitos, pirose, etc.)

- hidratação (oferta de líquidos, tipo e frequência)

- Sono e repouso

( ) calmo ( ) agitado ( ) chupa o dedo

( ) usa chupeta ( ) usa fraldinha

( ) outros

- Vida social e afetiva

- o oque sabe sobre fissura lábio-palatal?

(qual sua expectativa para o tratamento? Por que procurou o nosso serviço?)

- quais suas dúvidas?

- Como é o relacionamento com os pais?

( ) bom ( ) muito bom 
( ) prejudicado - em quais aspectos? ( pais severos demais, antiquados, não se importam, favorecem seus irmãos, são justos?)

- vocé estuda? ( ) sim ( ) não o que?

- faz amigos com facilidade? ( ) sim ( ) não

- sente-se muitos vezes sozinho? ( ) sim ( ) não

- condição do paciente:

$\begin{array}{ll}\text { ( ) tímido } & (\text { ) nervoso } \\ \text { ( ) expressivo } & (\text { ) tranqüilo } \\ \text { ( ) calmo } & (\text { ) alegria } \\ \text { ( ) ansioso } & (\text { ) tristeza }\end{array}$

- pratica algum esporte? ( ) sim ( ) não - qual sua religião?

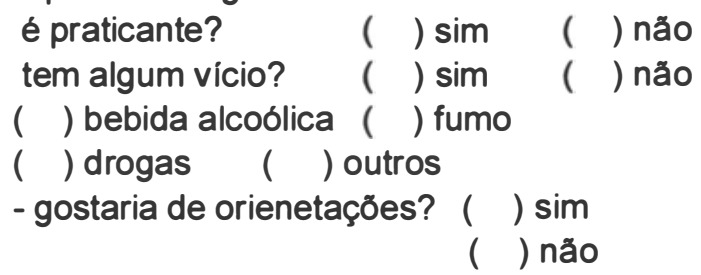

- como é para vocé sua imagem corporal?

- já iniciou atividade sexual? ( ) sim ( ) não

- como satisfaz sua necessidade sexual?

- o que sabe sobre doença sexualmente transmissivel?

\section{II - Exame Físico de Enfermagem

- Peso PC FC FR \\ Altura P1 Temp. PA}

- Pele e anexos (coloração, turgor, edema, lesőes, unhas e higiene)

- Postura

- Desenvolvimento neuro-psico-motor

- Cabeça:

- Fontanela (deprimida, abaulada, consolidada)

- Couro cabeludo e cabelos (sujidades, lesões, pediculose, outros)

- Olhos (secreção, simeetria, outros)

- Deficiência visual (início, primeiros sintomas)

- Nariz (higiene, secreção, lesões, outros)

- Orelhas (sujidade, secreção, lesões, outros)

- Deficiência auditiva (início, primeiros sintomas)

- Boca (lesões, higiene, outros)

- Pescoço (gánglios, outros)

- Tórax (simetria, expansão, tipo de respiração)

- Abdomen (flácido, globoso, timpânico, cicatriz umbilical, outros)

- Genitais (higiene, lesões, outros)

- Nádegas e ånus (alterações)

- Membros superiores (movimentação, simetria, outros)

- Membros inferiores (movimentação, simetria, outros)

III - Problemas Levantados

IV - Conduta de Enfermagem 